\title{
Microstructural evolution in the fine-grained region of the Siple Dome (Antarctica) ice core
}

\author{
R.W. OBBARD, ${ }^{1}$ K.E. SIEG, ${ }^{1}$ I. BAKER,${ }^{1}$ D. MEESE,${ }^{1,2}$ G.A. CATANIA ${ }^{3}$ \\ ${ }^{1}$ Thayer School of Engineering, Dartmouth College, Hanover, New Hampshire 03755-8000, USA \\ E-mail: rachel.w.obbard@dartmouth.edu \\ ${ }^{2}$ Climate Change Institute, University of Maine, Sawyer Environmental Research Building, Orono, Maine 04469-5764, USA \\ ${ }^{3}$ Institute for Geophysics (UTIG), John A. and Katherine G. Jackson School of Geosciences, University of Texas at Austin, \\ J.J. Pickle Research Campus, Bldg 196, 10100 Burnet Road (R2200), Austin, Texas 78758-4445, USA
}

\begin{abstract}
An in-depth analysis of seven samples from the Siple Dome (Antarctica) ice core, using optical microscopy and electron backscatter diffraction, illustrates rotational recrystallization or polygonization in the fine-grained region of the core between 700 and $800 \mathrm{~m}$. Between 640 and $700 \mathrm{~m}$, the microstructure is characterized by a bimodal grain-size distribution and a broken girdle fabric with evidence of polygonization. From 727 to $770 \mathrm{~m}$, mean grain size decreases and a single-maximum fabric is found, and, by $790 \mathrm{~m}$, mean grain size has again increased and a multiple-maxima fabric manifests itself. We compare grain-size distribution, $c$ - and a-axis orientation, and misorientation between adjacent grains. We found that misorientations between adjacent grains in the $727-770 \mathrm{~m}$ region were predominantly low-angle and typically around a common a-axis, suggesting polygonization. This conclusion is supported by radar evidence of a physical disturbance at $757 \mathrm{~m}$, which may be correlated with higher than usual strain in the $700-800 \mathrm{~m}$ range. Below $770 \mathrm{~m}$, larger less regular misorientations and textural evidence show that migration recrystallization is the primary recrystallization mechanism.
\end{abstract}

\section{INTRODUCTION}

Siple Dome, Antarctica, is located near the edge of the Ross Ice Shelf $\left(81^{\circ} 40^{\prime} \mathrm{S}, 148^{\circ} 49^{\prime} \mathrm{W} ; 621\right.$ m a.s.I.), on an east-west ridge between Kamb and Bindschadler Ice Streams, which are part of a larger system that transports the majority of the flowing ice from the West Antarctic ice sheet to the Ross Ice Shelf (Scambos and others, 1998; Pettit, 2003). Mean accumulation on Siple Dome is $13.5 \mathrm{~cm} \mathrm{a}^{-1}$, and the average annual surface air temperature is $-24.5^{\circ} \mathrm{C}$ (Taylor and others, 2004a).

Information about the ice-flow history of Siple Dome and its environs is recorded in the geometry of its internal layers (e.g. Nereson, 2000; Catania and others, 2010) which are assumed to be isochronous (e.g. Plewes and Hubbard, 2001). These data, obtained from ice-penetrating radar surveys, reveal dynamic ice-stream behavior on the edges of Siple Dome. However, the continuity of internal layers across the central portion of the dome up to depths of $\sim 700 \mathrm{~m}$ suggests Siple Dome has not been overrun with fastflowing ice streams for at least 10000 years (Nereson and others, 1998). In addition, the characteristic ice-divide bump in the internal layer pattern suggests long-term ( $\sim 5000$ years) stability of the Siple Dome divide position (Nereson and others, 1998). Isochrones across the central portion of Siple Dome were not visible below $\sim 700 \mathrm{~m}$ in previous radar surveys, owing to limited instrument resolution.

Glaciers are natural archives of atmospheric change, and their stratigraphy, ion and isotope chemistry and dust content provide important information about paleoclimate. To properly interpret this information, the physical evolution of the ice from its deposition as snow, through its compaction and metamorphism into firn and then ice must be understood. The chemistry and microstructure of the ice are inexorably linked. An example of microstructure affecting chemistry is first seen in the firn, where the gas chemistry, important for dating ice and studying past climate, is a function of the pore close-off depth (Sowers and others, 1992). Chemistry also affects the microstructure, something which has been observed by various groups for a number of solute species found in natural ice. For example, Paterson (1991) explored the characteristics of glacial period ice from a number of cores and concluded that both sulfate and chloride impede grain boundary migration and grain growth. Alley and others (1986) argued that the reduction in grain growth rate and concomitant reduction in grain size in Wisconsin ice from Dome C, Antarctica, was due to impurity drag resulting from the high concentrations of soluble impurities, including sodium and chloride. In the Greenland Ice Sheet Project 2 (GISP2) core, Alley and Woods (1996) found that something associated with forest fires, possibly ammonium, affects grain growth. Obbard and Baker (2007) found that calcium compounds in the grain boundaries of the fine-grained glacial layers of Vostok (Antarctica) ice affect grain-boundary mobility and help explain the development of the discontinuous microstructure between glacial and interglacial period ice. Laboratory tests have added further evidence that soluble impurities affect grain growth, and have shown that the effect depends on solute species and concentration as well as on temperature relative to the eutectic point of the solute (Alley and others, 1986; Nasello and others, 2007). Iliescu and others (2003) showed that sulfuric acid (0.07-0.170 ppm) decreases grain boundary mobility in ice and retards the nucleation of new grains. Nasello and others (2007) examined the effects of potassium chloride and found that at low concentrations (e.g. $0.02 \mathrm{ppm}), \mathrm{KCl}$ increases grain boundary mobility, while at higher concentrations (e.g. 0.2 ppm) grain boundary mobility decreases.

Microstructure consists of texture (grain size and shape) and fabric (preferred crystal orientation). Strain, a response to applied stress, affects both texture and fabric (Humphreys and Hatherly, 2004). Initially, crystal orientation in meteoric 
ice is random, but preferred orientations develop to accommodate stress in the ice sheet. Ice deforms primarily via dislocation glide on the basal plane. Resistance to shear on a non-basal plane, such as the prismatic or pyramidal plane, is up to 100 times greater than the resistance to shear on the basal plane (Higashi and others, 1968).

Stress drives the movement of dislocations within a grain (or crystal), while adjacent grains, oriented differently, act as constraints. This produces strain incompatibility between grains (Hutchinson, 1977) and activates processes such as diffusion, dislocation climb or grain translation, which produce internal rotation and further slip within the constrained grain. This process takes place at a different rate within each grain, depending on the original crystal orientation with respect to the applied stress. Overall, deformation in ice sheets leads to preferred orientation, where the $c$-axes rotate towards the direction of compression and away from the direction of tension. Either a single maximum or a girdle fabric develops with increasing depth (Wang and others, 2003; Gow and Meese, 2007a). The single maximum is found in deeper sections of an ice core where simple shear has become the dominant stress state (Pettit and Waddington, 2003). A girdle fabric, where the $c$-axes lie in a circle or plane, is produced when the stress state is uniaxial longitudinal tension, and the tension axis is normal to the girdle (Alley, 1988).

The microstructure of the Siple Dome core has been studied previously using visual stratigraphy, automated fabric analysis on vertical thin sections and sonic logging (DiPrinzio and others, 2005; Gow and Meese, 2007a; Pettit and others, 2011). The firn-ice transition occurs at $55 \mathrm{~m}$, where the mean crystal cross-section area is $0.074 \mathrm{~cm}^{2}$ and the density is $0.83 \mathrm{~g} \mathrm{~cm}^{-3}$ (Gow and Meese, 2007a). Grains are equiaxial and grain area is linearly proportional with time to $\sim 201 \mathrm{~m}$ depth $\left(0.28 \mathrm{~cm}^{2}\right.$ ) (DiPrinzio and others, 2005; Gow and Meese, 2007a). A preferred crystal orientation, or fabric, begins to develop at a fairly shallow depth. Clustering of the $c$-axes around the vertical is seen as shallow as $22 \mathrm{~m}$, and broad $c$-axis clustering is seen around $99 \mathrm{~m}$ (DiPrinzio and others, 2005; Gow and Meese, 2007a). The mean grain size continues to increase with depth, a vertical girdle fabric develops, and grain boundaries become more irregular by $221 \mathrm{~m}$ (DiPrinzio and others, 2005; Gow and Meese, 2007a). Gow and Meese (2007a) noted a significant decrease in grain size $\left(0.39 \mathrm{~cm}^{2}\right)$ at $261 \mathrm{~m}$ and significant evidence of strain within crystals (undulose extinction on optical thin sections). Below this depth, the mean grain area again increases until $\sim 700 \mathrm{~m}$. There is an abrupt decrease in mean grain size between $703 \mathrm{~m}$ $\left(0.23 \mathrm{~cm}^{2}\right)$ and $790 \mathrm{~m}\left(0.47 \mathrm{~cm}^{2}\right)$, which is accompanied by a change in fabric from a vertical girdle to a strong single maximum (DiPrinzio and others, 2005; Gow and Meese, 2007a). At greater depths, much larger crystals are found, along with strong evidence of migration recrystallization (DiPrinzio and others, 2005).

In addition to the grain-size decrease and fabric change, layers of volcanic ash and dust are also found between 700 and $800 \mathrm{~m}$ (Gow and Meese, 2007a). Tephra particles found in an ash layer in the core were found to have an average size of $50 \mu \mathrm{m}$ and it is believed that ash concentration is similar to that in Byrd core volcanic debris bands, $\sim 4 \times 10^{-5} \mathrm{~g} \mathrm{~cm}^{-3}$ (Gow and Meese, 2007b). However, while fine-grained ice is found in ash layers, there are also finegrained layers without visible ash.
Table 1. Depths of Siple Dome ice-core samples examined and approximate age, based on linear interpolation using Brook and others (2005)

\begin{tabular}{lcc}
\hline $\begin{array}{l}\text { Top depth } \\
\mathrm{m}\end{array}$ & $\begin{array}{c}\text { Bottom depth } \\
\mathrm{m}\end{array}$ & $\begin{array}{c}\text { Approximate age } \\
\text { ka }\end{array}$ \\
\hline 640.123 & 640.163 & 12.92 \\
670.030 & 670.120 & 14.81 \\
700.000 & 700.040 & 17.51 \\
727.410 & 727.470 & 23.81 \\
750.000 & 750.072 & 26.78 \\
770.150 & 770.200 & 30.17 \\
790.350 & 790.390 & 33.39 \\
\hline
\end{tabular}

The purpose of this paper is to determine the mechanism resulting in a decrease in mean grain size between 700 and $790 \mathrm{~m}$ in the Siple Dome core.

\section{EXPERIMENTAL APPARATUS AND METHODS}

\subsection{Texture}

The Siple Dome A ice core is stored at $-35^{\circ} \mathrm{C}$ at the US National Ice Core Laboratory (NICL). Seven samples were transferred from NICL to Dartmouth at transport temperatures not exceeding $-10^{\circ} \mathrm{C}$. In Dartmouth's Ice Research Laboratory, the samples were stored and prepared for analysis at $-20^{\circ} \mathrm{C}$.

The Siple Dome core was dated using annual layering through $514 \mathrm{~m}$ (i.e. through the Holocene period) (Taylor and others, 2004a). Below this depth, approximate dating can be derived from control points calculated by comparing methane and $\delta^{18} \mathrm{O}$ gas age with that from GISP2 (Brook and others, 2005). There are 22 control points beginning at $514.78 \mathrm{~m}(8.33 \mathrm{ka})$ and ending at $919.88 \mathrm{~m}$ (56.70 ka) (Brook and others, 2005). Sample depths are shown in Table 1 with their approximate ages calculated by our group using simple linear interpolation from the control points given in Brook and others (2005). This method produces dates different from those in the discrete depth ion-chemistry data (P. Mayewski, http://nsidc.org/data/waiscores/pi/mayewski. html) but adequate for our purposes.

Vertical thin sections were prepared and then photographed on a light table through crossed polarizers. Grain size was measured using multiple images of each sample (taken at different angles of rotation between the polarizers) and using the pixel-counting area measurement utility of an image-processing application, Image SXM (Rasband, 2006; S.D. Barrett, http://www.liv.ac.uk/ sdb/ImageSXM). No correction was made for grains intersected by thin-section edges or for the limitations associated with measuring grain size in only two dimensions.

\subsection{Fabric}

For orientation analysis, electron backscatter diffraction (EBSD) on an FEI XL-30 environmental scanning electron microscope (SEM) with a liquid-nitrogen-chilled cold stage was used. The technique for sample preparation and scanning electron microscopy of uncoated ice is described in detail in Iliescu and others (2004) and Obbard (2006). Samples for analysis were rough-cut slightly larger than the 


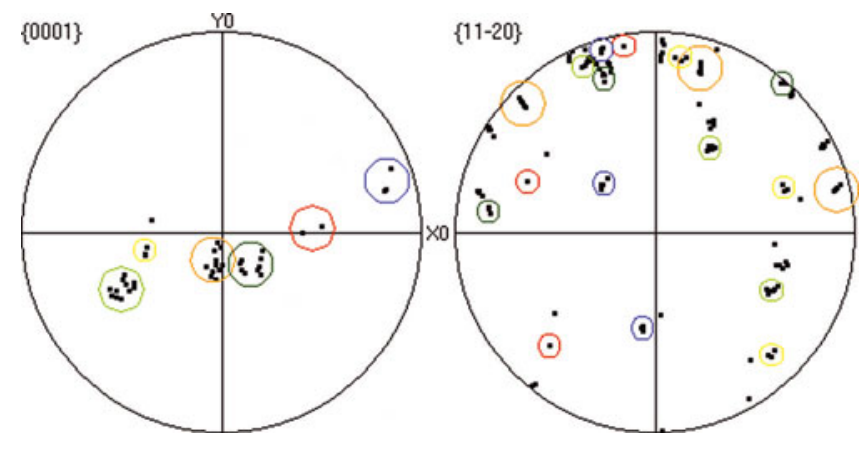

Fig. 1. Pole figures (top) and grain-mapping schematic (bottom) for one sample from $670 \mathrm{~m}$. 43 unique orientations are plotted in the pole figures. Poles from adjacent grains are circled.

desired final dimension using a bandsaw, then transferred to a HEPA-filtered laminar-flow clean-room hood for surface smoothing with a pre-cleaned standard safety razor. The SEM specimens were stored in a sealed container at $-25^{\circ} \mathrm{C}$ for $\sim 24$ hours before examination in the SEM. In the SEM, a specimen was initially chilled to a temperature of approximately $-75 \pm 5^{\circ} \mathrm{C}$ while vacuum conditions were achieved. Then the SEM chamber was placed in environmental mode, and the cold-stage temperature increased to $-45 \pm 5^{\circ} \mathrm{C}$ for the duration of analysis.

The EBSD data are reported in two ways. Pole figures display $c$ - and a-axis information for each depth (Fig. 3, further below). Misorientation is defined as the smallest angle by which one crystal can be rotated around a common axis to achieve lattice coincidence with a second crystal. The misorientation angles are presented in a histogram (Fig. 4, further below) which compares the distribution of rotations between adjacent grains (correlated data, shown with bars), with the distribution of misorientation angles between random pairs of grains in the dataset (uncorrelated data, dashed line) and the theoretical random distribution curve for a system of randomly oriented hexagonal grains (solid line). The theoretical distribution curve is produced by the HKL software according to the procedures of Mackenzie (1958) and Morawiec (1995). An uncorrelated distribution that differs from the theoretical random indicates a preferred orientation (or fabric) overall in the material, which would also be observed on the pole figures. A distribution of correlated misorientations that differs from that of the uncorrelated misorientations, however, suggests a special relationship between adjacent grains such as that resulting from polygonization. Although every effort was made to collect only one EBSD pattern from each grain observed in the secondary electron image while the sample was in the SEM, the misorientation between adjacent grains was used to eliminate patterns that might represent the same grain. Obbard (2006) found that within a single crystal, there was a change in specimen orientation of $\sim 1^{\circ}$ over a span of $2 \mathrm{~mm}$ corresponding to $\mathrm{a} \sim 1^{\circ}$ orientation noise, consistent with that indicated by Bate and others (2005). Therefore, all EBSD patterns differing in orientation by $<1^{\circ}$ were assumed to represent the same grain.

Due to the large crystal size, a manual (rather than automatic) mapping procedure was used to collect nine EBSPs in a $3 \times 3$ array from each of nine contiguous $600 \mu \mathrm{m} \times 600 \mu \mathrm{m}$ areas across each sample. Thus, a pattern was collected every $200 \mu \mathrm{m}$ when possible. Patterns could not be collected from pores or grain boundaries. This mapping method resulted in superfluous data when adjacent points fell within the same grain. In order not to over-represent an orientation, the extra points needed to be identified and nullified. Misorientation data were used to identify adjacent points having the same orientation. If two points had a misorientation of $1^{\circ}$ or less, they were considered to be identical, and all points representing the same orientation were nullified except for one. The resulting subset of unique orientations was used to diagram grain boundaries for the sample, with lines between separating unique orientations. This process was repeated in each area examined, producing a $0.6 \mathrm{~mm} \times 5.4 \mathrm{~mm}$ diagram of grain boundaries.

The pole figure analysis performed for each sample is described below, using one sample as an example. Figure 1 includes upper-hemisphere pole figures showing the $c$ - and a-axis orientations, $\{0001\}$ and $\{11-20\}$, respectively, for one of six samples from $670 \mathrm{~m}$. Due to hexagonal symmetry, each unique crystal orientation is represented by one point on the $c$-axis pole figure and three points on the a-axis pole figure. Note that these pole figures contain distinct clusters of poles. These clusters, identified by colored circles in Figure 1, were compared to the grain boundary diagrams, and both in this sample and many others (700-790 m), the poles within each cluster happen to originate from adjacent grains on the sample.

We then compared the angular spread of the points within each cluster and the misorientation between separate clusters (their centers). Misorientation within a given $c$-axis cluster for the sample shown in Figure 1 ranged from $<1^{\circ}$ to $16^{\circ}$ (mean $7^{\circ}$ ), while misorientation within a given a-axis cluster ranged from $<1^{\circ}$ to $8^{\circ}\left(\right.$ mean $\left.3^{\circ}\right)$. The $c$-axis misorientation between different clusters ranged from $36^{\circ}$ (light green to yellow in Fig. 1) to $79^{\circ}$ (orange to blue), with a mean of $51^{\circ}$.

\subsection{Radar data}

Radar data were acquired along the northern flank of Siple Dome as part of a different study focused on grounding-line behavior along the northern and southern edges of Siple Dome (Catania and others, 2010). The radar system is custom-built, low-frequency, ground-based and is useful for imaging deep internal layers with a center frequency of $3 \mathrm{MHz}$. At this frequency the radar antennae provide a pulse wavelength in ice of $\sim 56 \mathrm{~m}$. To improve the signal-to-noise ratio, our data consist of 1600 waveforms recorded over a horizontal spacing of $\sim 17 \mathrm{~m}$. As a result, steeply dipping stratigraphy within this horizontal distance can be aliased. Further processing includes removal of the mean waveform (to limit interference due to instrumentation artifacts) and application of a bandpass filter. We convert the two-way travel time to depth by assuming a radar wave speed in ice of $168 \mathrm{~m} \mathrm{ss}^{-1}$. We account for faster wave speeds in the firn column using depth-density measurements from Siple Dome (Mayewski, http://nsidc.org/data/waiscores/pi/ mayewski.html) and the Looyenga mixing equation (Glen and Paren, 1975).

\section{RESULTS AND OBSERVATIONS}

\subsection{Texture}

The vertical thin sections we produced were very similar in appearance to those shown in DiPrinzio and others (2005) and Gow and Meese (2007a). Grain boundaries were 
Table 2. Mean and median grain area, along with standard deviation for each depth sampled, and mean grain area based on grain radius found in DiPrinzio and others (2005). Because the grain size was large relative to sample size, 100 grains could not be measured in each sample

\begin{tabular}{lcrrrc}
\hline Depth & $\begin{array}{c}\text { Number of } \\
\text { grains } \\
\text { measured }\end{array}$ & $\begin{array}{c}\text { Mean } \\
\text { grain } \\
\text { area }\end{array}$ & Std dev. & Median & $\begin{array}{c}\text { Mean grain area } \\
\text { from DiPrinzio } \\
\text { and others (2005) }\end{array}$ \\
$\mathrm{m}$ & & $\mathrm{mm}^{2}$ & $\mathrm{~mm}^{2}$ & $\mathrm{~mm}^{2}$ & $\mathrm{~mm}^{2}$ \\
\hline 640 & 34 & 36.1 & 54.2 & 18.3 & 120 \\
670 & 70 & 20.4 & 33.8 & 7.9 & 125 \\
700 & 63 & 20.3 & 25.9 & 13.1 & 16 \\
727 & 162 & 10.2 & 9.5 & 8.6 & 13 \\
750 & 110 & 9.0 & 9.5 & 6.2 & 13 \\
770 & 90 & 11.6 & 15.0 & 6.0 & 20 \\
790 & 88 & 17.6 & 17.5 & 11.1 & 35 \\
& & & & & \\
\hline
\end{tabular}

irregular (sutured, tortuous or wavy), and extinction (color within a grain) was undulose, indicating strain and hence bending or buckling of the basal plane in response to stress (Gow and Meese, 2007a). Grain size (area) for each depth is shown in Table 2, along with grain sizes derived from DiPrinzio and others (2005), using their graph of grain radius versus depth. DiPrinzio and others (2005) reported grain size as the radius of a circle having the same area as the average grain size measured. They also used a correction factor (in the larger-grained samples) to account for the grains that were cut off by the boundaries of the thin section, and noted that this correction may have affected mean grain size (but not the data trend), which may explain the large apparent grain size at 640 and $670 \mathrm{~m}$.

The large standard deviations in the 640-670 m samples reflect a mixture of smaller and much larger grains. Gow and Meese (2007a) also noted this bimodal distribution at $640 \mathrm{~m}$. Table 3 shows the mean, standard deviation and median values for grain area excluding large grains $\left(>60 \mathrm{~mm}^{2}\right)$. The samples from 727 and $750 \mathrm{~m}$ did not contain the larger grains and had a more consistent, smaller grain size. For the other samples, excluding large grains results in the mean grain size approaching the median.

Figure 2 breaks down the grain sizes into $10 \mathrm{~mm}^{2}$ bins. The $640 \mathrm{~m}$ sample has a bimodal distribution, where a significant number of grains have an area of $61 \mathrm{~mm}^{2}$ or greater, while the majority have an area between 0 and $30 \mathrm{~mm}^{2}$. The 670 and $700 \mathrm{~m}$ samples also have a few much larger grains. Nonetheless, the grain size in all three samples is skewed towards the smaller end, and the sample distributions become narrower and centered in the small grain area bins as the depth increases to $750 \mathrm{~m}$. Below $750 \mathrm{~m}$, the distributions become slightly broader and begin to include larger area grains, again shifting the median size to greater values.

\subsection{Fabric}

The data gleaned from EBSD are useful for distinguishing between recrystallization mechanisms, as discussed here and seen in our results which follow.

Polygonization occurs when interactions of dislocation stress fields cause the dislocations to align, producing subgrain boundaries and additional new grains that differ in orientation from the $c$-axis of the original grain by only a
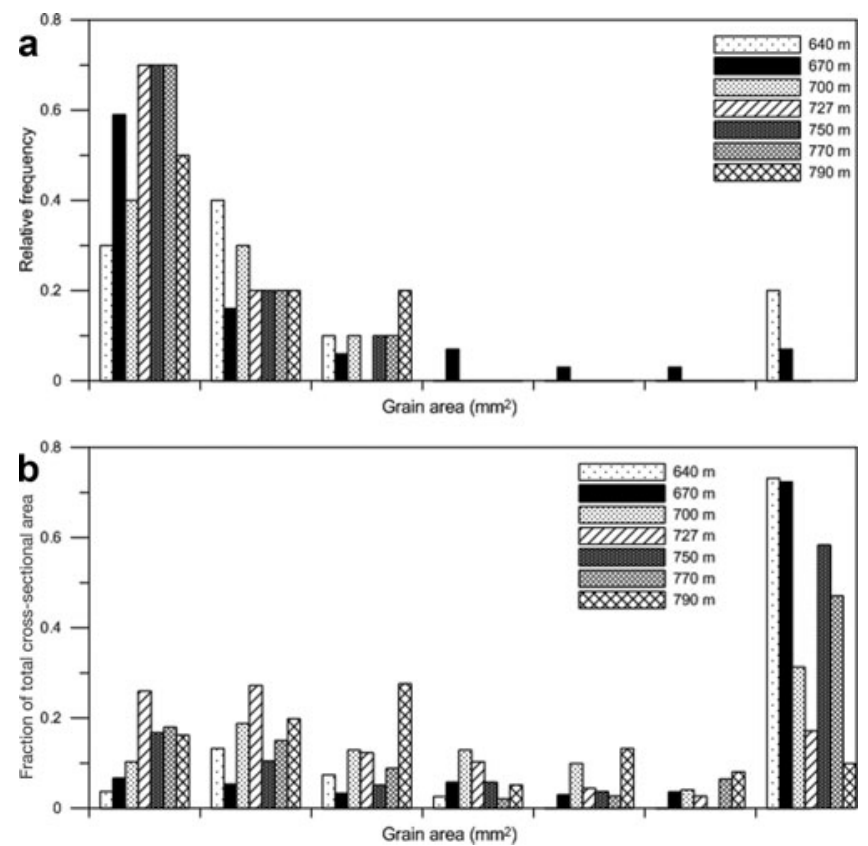

Fig. 2. For each of the seven depths tested, (a) fraction of all grains measured having a given area (range), and (b) fraction of total sample cross-sectional area that was found in each grain area range.

few degrees, with rotation around an a-axis. In fact, because of its nature, we would expect polygonization to produce $c$ and a-axis clusters with somewhat less misorientation within the latter. Polygonization can also explain the lack of increase in mean grain size, despite increasing depth and age, because larger grains split into smaller ones (Alley and others, 1997; Castelnau and others, 1997; Gow and others, 1997). Polygonization has been specifically identified between 1551 and $1745 \mathrm{~m}$ at GISP2 (Obbard, 2006), at $650 \mathrm{~m}$ in the European Greenland Icecore Project (GRIP) (Castelnau and others, 1997), and between 400 and $1200 \mathrm{~m}$ at Byrd, Antarctica (Alley and others, 1995). Polygonization may cause a widening of an existing $c$-axis fabric (e.g. a single maximum) (De La Chapelle and others, 1998), and, because individual larger grains split into two or more smaller grains of similar orientation, small clusters of poles on both $c$ - and a-axis pole figures may also be produced.

Migration recrystallization, the nucleation and growth of new grains amongst larger, older ones, can also produce multi-maxima or clustering in pole figures (Alley, 1988). An examination of nearest-neighbor misorientations is useful for

Table 3. Grain area mean and median for each depth sampled excluding grain areas greater than $61 \mathrm{~mm}^{2}$

\begin{tabular}{lcrr}
\hline Depth & $\begin{array}{c}\text { Mean grain area } \\
\mathrm{mm}^{2}\end{array}$ & $\begin{array}{c}\text { Std dev. } \\
\mathrm{mm}^{2}\end{array}$ & $\begin{array}{c}\text { Median } \\
\mathrm{mm}^{2}\end{array}$ \\
\hline 640 & & & \\
670 & 14.8 & 8.0 & 14.4 \\
700 & 12.8 & 14.0 & 7.0 \\
727 & 15.2 & 12.6 & 12.1 \\
750 & 10.2 & 9.5 & 8.6 \\
770 & 9.0 & 9.5 & 6.2 \\
790 & 9.5 & 10.0 & 5.2 \\
& 14.9 & 12.3 & 10.6 \\
\hline
\end{tabular}



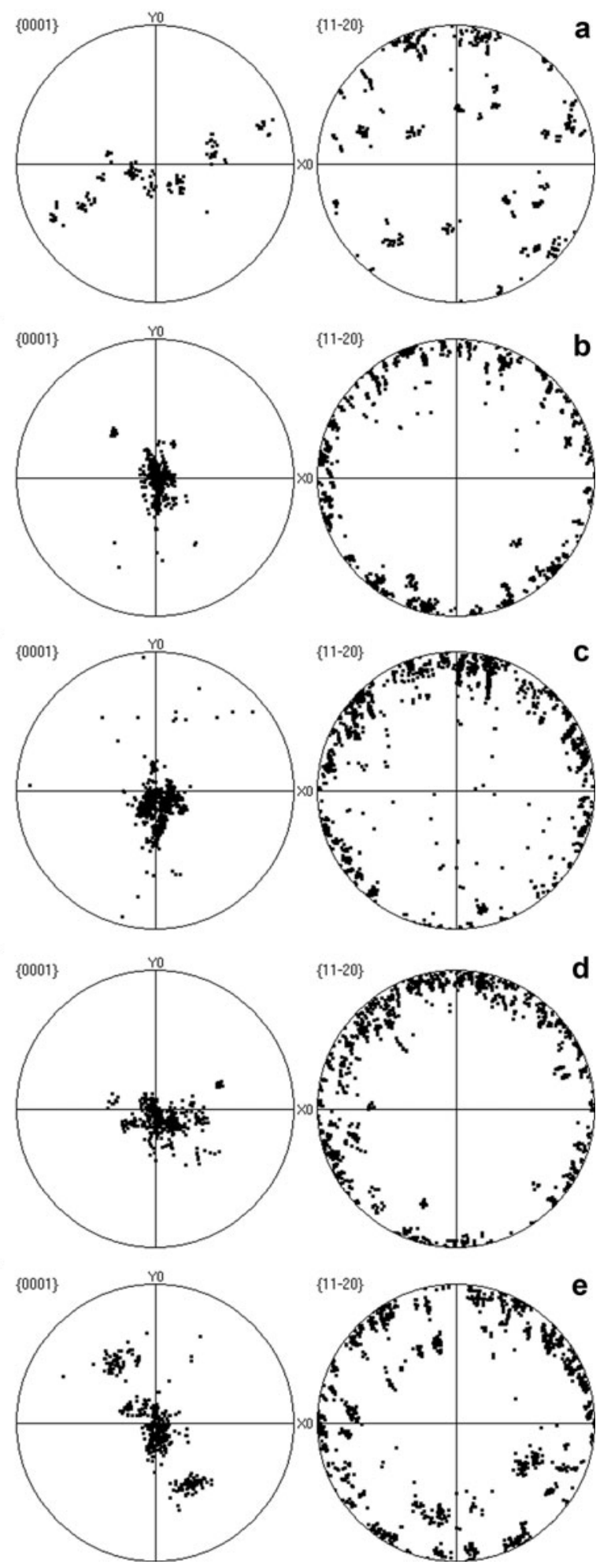

Fig. 3. Pole figures for (a) $670 \mathrm{~m}$ ( 6 samples, 131 grains), (b) $700 \mathrm{~m}$ (7 samples, 335 grains), (c) $727 \mathrm{~m}$ (5 samples, 391 grains), (d) $750 \mathrm{~m}$ (6 samples, 367 grains) and (e) $770 \mathrm{~m}$ (6 samples, 378 grains).

distinguishing between migration recrystallization and polygonization. The former tends to produce large grains with tortuous grain boundaries, and the repeated intersection of a single large, complex grain by a plane might resemble a set of similarly oriented smaller grains, with clusters on both $\{0001\}$ and $\{11-20\}$ pole figures. However, there would be no pattern in the location of these grains, i.e. similarly oriented grains would not necessarily be adjacent to one another. Thus, it is unlikely that migration recrystallization is the cause of the pole figure clusters associated with adjacent grains.

Due to the large grain size, insufficient grain orientation data were available from the $640 \mathrm{~m}$ sample to construct a pole figure. Gow and Meese (2007a), however, report a multi-maxima fabric at this depth. Pole figures for the other samples we tested are shown in Figure 3.

Pole figures for $670 \mathrm{~m}$ (Fig. 3) reveal clustering of both c- and a-axes. The misorientation histogram (Fig. 4) shows a significant number of low angle misorientations $\left(<10^{\circ}\right)$ between adjacent grains, as well as some high angle misorientations $\left(35-80^{\circ}\right)$. The low misorientation angles within pole figure clusters represent adjacent grains misoriented by $\sim 2^{\circ}$ such that there was a net orientation change from one end of a region of adjacent grains to the other. The angular spread was dependent on the size of the region, with the larger regions tending to have larger angular spreads. These low angle misorientations suggest polygonization, according to Alley and others (1995), who established that the misorientation angle distribution reveals the dominant grain-size reducing mechanism.

Interestingly, even the large misorientations $\left(35-80^{\circ}\right)$ between different clusters are primarily due to differences in $c$-axis orientation. Often, several different clusters on the $c$-axis pole figure shared some a-axis locations on the \{11-20\} pole figure. This may mean that even larger misorientations originated in polygonization around a common a-axis.

The sample from $700 \mathrm{~m}$ is different in that it has a singlemaximum $C$-axis fabric (Fig. 3) and a significantly smaller mean grain size. This depth had a high frequency of low angle misorientations $\left(<10^{\circ}\right)$ and a significant number of misorientations between $10^{\circ}$ and $30^{\circ}$ (Fig. 4). As in the $670 \mathrm{~m}$ sample, the low angle misorientations were primarily from c-axis variations between adjacent grains with a common a-axis. Larger misorientations were generally associated with differences in a-axis orientation.

These results agree with those obtained by DiPrinzio and others (2005) and Gow and Meese (2007a), which also show a reduction in grain size accompanied by a single-maximum fabric at $700 \mathrm{~m}$. The polygonization process would produce the reduction in mean grain size seen here. Typically, the transition from a vertical girdle to a single-maximum fabric has been attributed to a change in the stress state, from pure shear to simple shear (Alley, 1992).

In the sample from $727 \mathrm{~m}$, the $c$-axis fabric is again a single maximum (Fig. 4) and the increased strength of the fabric is reflected in the peak in uncorrelated misorientations. A higher proportion of the misorientations are low-angle for this depth than at $700 \mathrm{~m}$ (Fig. 4). The low angle misorientations can be attributed to polygonization. The larger misorientations are due to differences in a-axis orientation.

The single-maximum $c$-axis fabric is also found at $750 \mathrm{~m}$ (Fig. 4). Overall, the fabric of this sample was similar to those from 700 and $727 \mathrm{~m}$, but with an even greater proportion of low angle misorientations (Fig. 4). Based on their distribution, the low angle misorientations can be attributed to polygonization within larger original grains. In two of the six specimens tested, regions having adjacent grain misorientations, attributed to differences in c-axis orientation, between $45^{\circ}$ and $50^{\circ}$ were found. Importantly, this was also observed in the deeper sample $(770 \mathrm{~m})$ where in situ temperatures would permit migration recrystallization. 

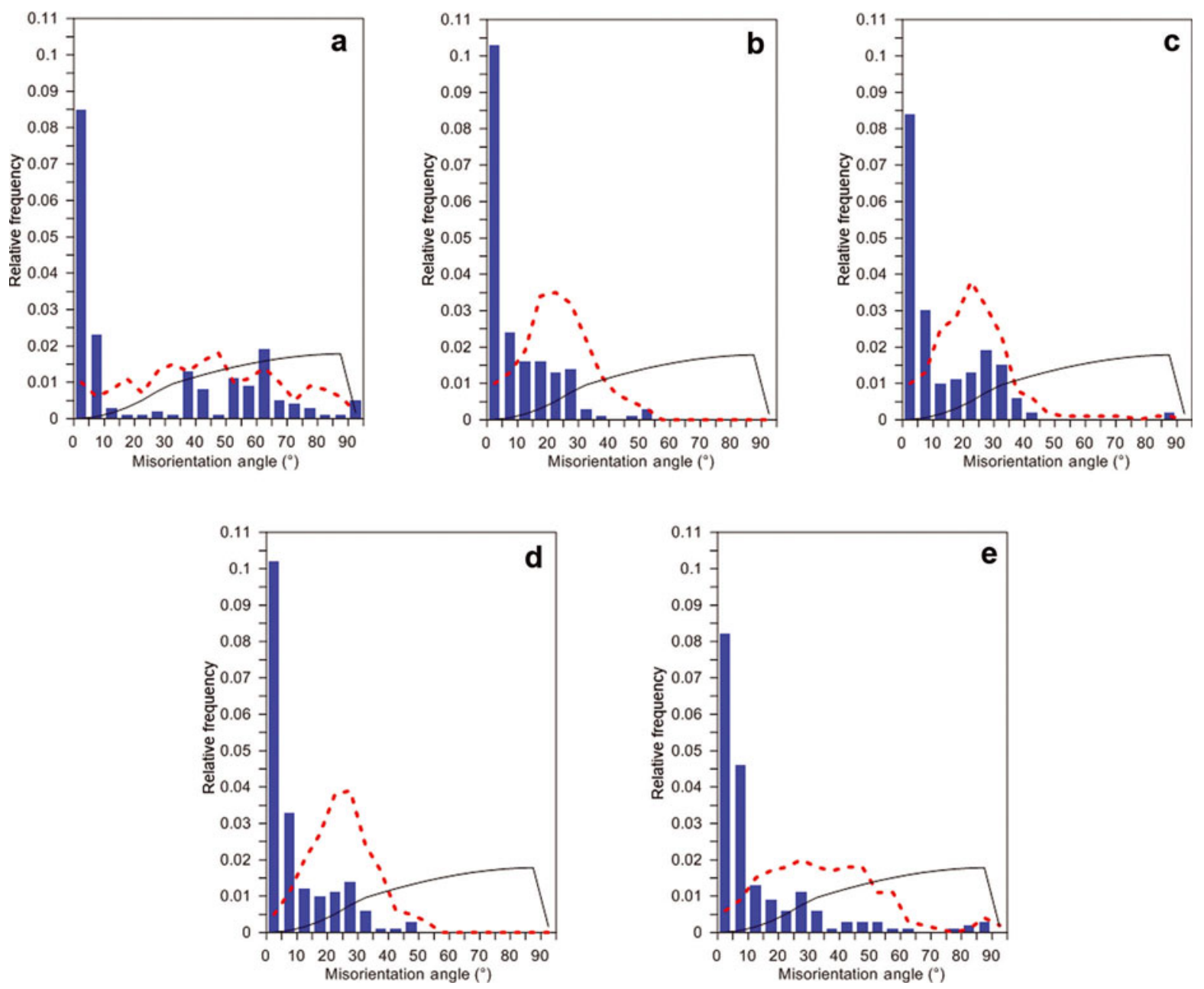

Fig. 4. Misorientation angle distribution for (a) $670 \mathrm{~m}$, (b) $700 \mathrm{~m}$, (c) $727 \mathrm{~m}$, (d) $750 \mathrm{~m}$ and (e) $770 \mathrm{~m}$, based on orientations shown in Figure 3 . Correlated values (blue) are between user-defined adjacent grains; uncorrelated values (dashed red line) are between 1000 randomly chosen pairs of measured grains. The random (theoretical) orientation (black line) is for a randomly oriented hexagonal crystal.

The $c$-axis fabric at $770 \mathrm{~m}$ (Fig. 4) may be classified as either a broken vertical girdle or a multiple maxima. The former would suggest a return to a state of uniaxial longitudinal tension; hence the latter seems more likely. A multiple maxima may represent grains produced by migration recrystallization, with large misorientations between those that are themselves experiencing polygonization, thus producing widely separated clusters. There is again a high proportion of low angle misorientations $\left(<10^{\circ}\right)$, but this time other misorientation angles are spread across the range $15-90^{\circ}$ and are due to $c$-axis tilting in some cases and $a$-axis rotation in others (Fig. 5).

EBSD data were not collected from the $790 \mathrm{~m}$ sample due to large grain size (few grains). DiPrinzio and others (2005) document a single-maximum fabric at this depth, but with a significant number of off-vertical poles, similar to our $770 \mathrm{~m}$ $c$-axis pole plot (Fig. 4). This is consistent with the onset of migration recrystallization while polygonization is still taking place.

\subsection{Impurities}

Glacial ice contains soluble and insoluble impurities, which are both of climatological interest and an important factor in the microstructural evolution of ice (Fisher and Koerner, 1986). Continental dust, sea-salt aerosols, and species formed in the atmosphere are most common, but volcanic eruptions contribute both insoluble particles and $\mathrm{H}_{2} \mathrm{SO}_{4}$ (Kreutz and Mayewski, 1999; Siggaard-Andersen, 2005). In SEM studies of ice from Antarctica (e.g. Byrd and Vostok), 5-10 $\mu \mathrm{m}$ white spots are commonly observed on crystallographic facets in the grain interiors and along grain boundaries, and sometimes coalesce to form filaments in grain boundaries during sublimation (Cullen, 2002). EDS reveals that these contain predominantly $\mathrm{Na}, \mathrm{S}, \mathrm{Cl}$ and $\mathrm{Mg}$. Larger particulates $(\sim 60 \mu \mathrm{m})$ are sometimes found within the lattice and these consist primarily of $\mathrm{Si}$ and $\mathrm{Al}$ with $\mathrm{K}, \mathrm{Na}$ and $\mathrm{C}$ and occasionally $\mathrm{Cl}, \mathrm{Mg}, \mathrm{Fe}, \mathrm{S}$ and Ti. These are generally attributed to continental dust or volcanic ash.

The presence of certain impurities above critical levels affects glacier flow and ice deformation, so it is important to analyze the type of impurities present and their location within the microstructure. In general, the effect of the impurities on mean grain size is dependent on the relationship between their volume fraction and size (Humphreys and Hatherly, 2004). There have been numerous studies of the effect of impurities on mechanical processes in ice (Jones and Glen, 1969; Nakamura and Jones, 1970, 1973; Hooke and others, 1972; Baker and Gerberich, 1979; Iliescu and others, 2003; Jacka and others, 2003; Song and others, 2004, 2005a,b, 2006, 2007a,b, 2008; Li and others, 2009). However, ion chromatography of discrete samples of the pre-Holocene Siple Dome A core suggests that no unusually 


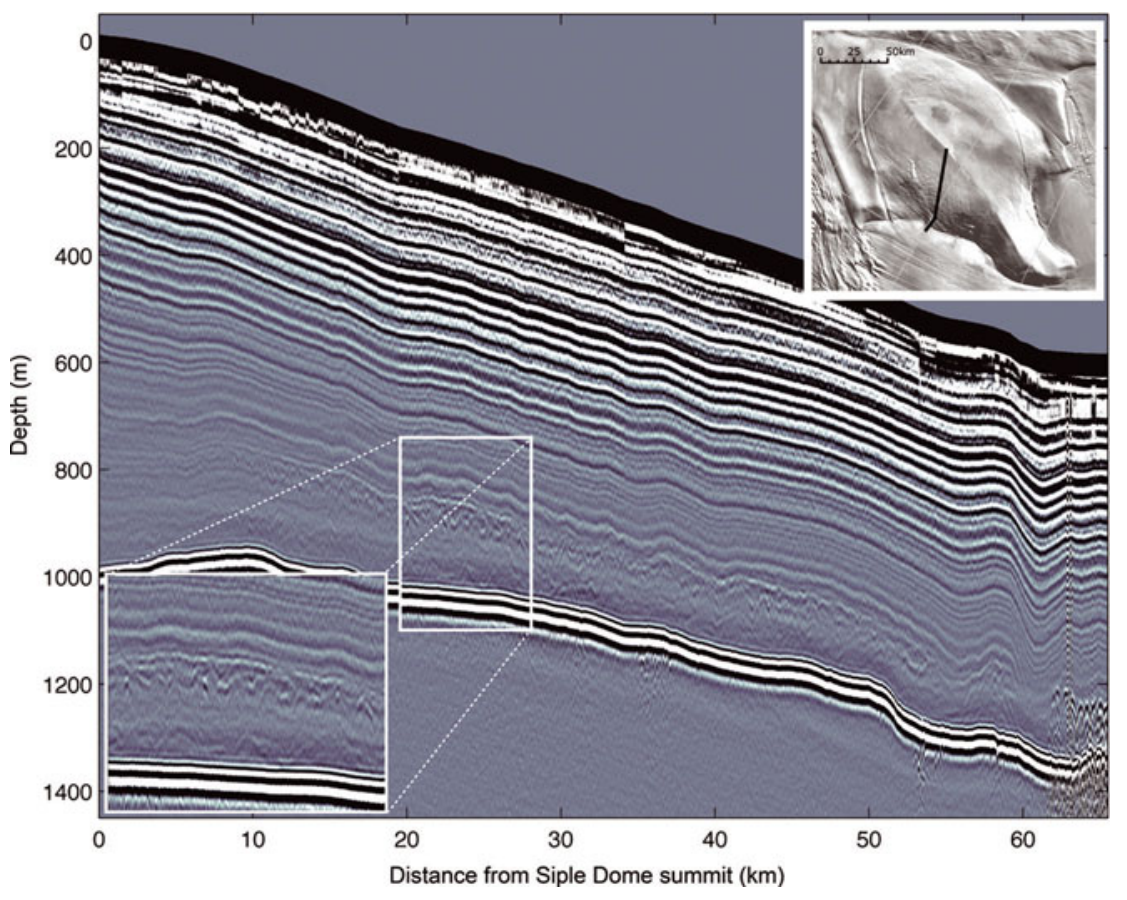

Fig. 5. $3 \mathrm{MHz}$ radar data across the northern flank of Siple Dome. Data in the upper $\sim 50 \mathrm{~m}$ (shown as a black band) are obscured by the direct wave from the transmitter. Inset shows location relative to Siple Dome. The grounding line was crossed at $\sim 60 \mathrm{~km}$ and is characterized by basal crevasses and downwarped internal stratigraphy.

high concentrations of any major ion are present at the depths tested (Mayewski, http://nsidc.org/data/waiscores/pi/ mayewski.html). There is a somewhat higher concentration of $\mathrm{Ca}(10-20 \mathrm{ppb})$ at 700,727 and $750 \mathrm{~m}$ than elsewhere between 640 and $790 \mathrm{~m}$ (Mayewski, http://nsidc.org/data/ waiscores/pi/mayewski.html), but not nearly as much as found in fine-grained layers of the Vostok core (117$409 \mathrm{ppb})$. Nor did the SEM reveal impurities on the grain boundaries of these Siple Dome samples, except at 727 and $750 \mathrm{~m}$, where there was a single location in each that contained $\mathrm{Na}, \mathrm{Cl}, \mathrm{K}$ and $\mathrm{S}$. Although the Ca may play a role in limiting grain growth, as it seems to in the Vostok core, evidence that polygonization is the primary cause of reduced mean grain size in the Siple Dome A layers between 700 and $800 \mathrm{~m}$ is overwhelming.

A number of 20-100 $\mu \mathrm{m}$ (greatest dimension) $\mathrm{Si}-$, Na- Kand $\mathrm{Al}$-containing particles were also found in the crystal lattice. These are probably insoluble dust or ash. In their study of 300 specific volcanic ash and dust layers in the $700-800 \mathrm{~m}$ depth range in Siple Dome, Gow and Meese (2007b) measured an average particle size of $50 \mu \mathrm{m}$ in ash layers and $5 \mu \mathrm{m}$ in dust bands and identified peralkaline trachyte $\left(\mathrm{KAISi}_{3} \mathrm{O}\right)$ and alkaline feldspar $\left(\mathrm{NaAISi}_{3} \mathrm{O}_{8}\right)$, plus accessory minerals containing $\mathrm{K}, \mathrm{Na}, \mathrm{Mg}$, Fe, Mn, Ti, Zn, Li, $\mathrm{Cr}, \mathrm{Al}, \mathrm{Ca}$ and $\mathrm{Si}$. The samples studied here did not contain visible debris layers, but it is not surprising that they did contain some particles in the size range determined by Gow and Meese (2007b).

Inert, second-phase particles have been shown, both theoretically and empirically, to inhibit grain growth and grain-boundary migration in polycrystalline materials, including ice (Dunn and Walter, 1966; Gow and Williamson, 1976). Indeed, grain sizes are often found to be smaller in visually dirty ice than in clean ice of the same age (Gow and Williamson, 1976; Duval and Lorius, 1980). Initially, a causal relationship was drawn between the increase in particle concentration and the decrease in grain size across the Holocene-Wisconsin boundary in several ice cores (Koerner and Fisher, 1979). Later, however, two separate groups (Duval and Lorius, 1980; Alley and others, 1986) compared the intrinsic driving force for grain growth with the drag force from particles in ice. Alley and others (1986) concluded that at the particle concentrations present in typical clean glacier ice, the particles had little effect on grain growth. Even in visibly dirty glacier ice, which the samples examined here were not, the higher particle concentration does not always fully explain decreases in grain growth rate (Alley and others, 1986). Hence, while it is not surprising to find debris in the Siple Dome samples we studied, it is not the cause of the differences in microstructure observed.

\subsection{Radar data}

Previous radar data collected on Siple Dome found continuous isochrones to $700 \mathrm{~m}$ and an absence of any visible stratigraphy below that depth (Nereson and others, 1998). Our improved radar has a higher sampling frequency allowing layers to become visible to nearly the base of the ice sheet and allows comparison to ice-core characteristics at greater ice thicknesses. We find that the deepest continuous layer across Siple Dome is at $\sim 757 \mathrm{~m}$ depth. Below this, we observe an abrupt transition to discontinuous stratigraphy that appears to extend to the base of the ice sheet across the entire northern flank of the dome (Fig. 5). Other radar data previously reported for Siple Dome with the same radar system show similar stratigraphy on the southern flank of Siple Dome, close to its grounding line (Catania and others, 2010, fig. 3). The lack of continuous layers below $757 \mathrm{~m}$ is consistent with electrical conductivity measurements of the ice core by Taylor and Alley (2004) who report finding disturbed layers at $803 \mathrm{~m}$ depth. Layered stratigraphy is found below this disturbed zone (Taylor and 
Alley, 2004), but our radar system is unable to detect these layers, likely because the signal has been strongly attenuated through the disturbed stratigraphy.

The deepest continuous layer varies with depth in such a way as to create undulations that are not related to the bed or surface topography and instead may be due to deposition over the deeper disturbed stratigraphy. Because of the coarse horizontal spacing of our radar waveforms during acquisition, we believe that the disturbed stratigraphy has been aliased. As such, it is difficult to determine whether the stratigraphy is continuous and steeply dipping with respect to the present-day ice-sheet surface, or whether the radar is returning diffraction hyperbolae. Hyperbolae in radar data may result from scatter due to crevasses that are filled or bridged, and then buried by subsequent accumulation (e.g. Retzlaff and Bentley, 1993; Smith and others, 2002; Catania and others, 2005) or from isolated pockets of contrasting permittivity, such as from sediment or water inclusions in the ice (Clarke and others, 2000). We rule out this latter hypothesis because freezing temperatures are found at the base of Siple Dome (Engelhardt, 2004) that have persisted for long enough to refreeze any available water. Further, sediment is found in only the lower $2 \mathrm{~m}$ of core (Gow and Meese, 2007a). Tephra deposits found at the depths of the disturbed stratigraphy (Gow and Meese, 2007a) are widely deposited and will not cause the layer shape to be altered. Instead, these same tephra deposits have been used to explain the occurrence of a bright continuous reflector present throughout most of the West Antarctic ice sheet in radar data (Jacobel and Welch, 2005).

\section{DISCUSSION}

A significant decrease in mean grain size that is accompanied by a strengthening or change in fabric has been observed in many polar ice cores: GISP2, GRIP, NorthGRIP (North Greenland Icecore Project), Byrd, Siple Dome, Dome $\mathrm{C}$ and Vostok (Gow and others, 1997; Thorsteinsson and others, 1997; DiPrinzio and others, 2005; Bizet, 2006; Durand and others, 2007; Gow and Meese, 2007a; Obbard and Baker, 2007). In some (e.g. GRIP and Dome C), regions of relatively smaller grains are coincident with stronger fabric (Thorsteinsson and others, 1997; Durand and others, 2007). In others, the fabric is actually different in the finegrained layers. One such example is NorthGRIP, where the predominant fabric is a single maximum, but fine-grained layers have a girdle fabric (Bizet, 2006). At Vostok and Siple Dome, however, the opposite is true: a girdle fabric predominates but a single maximum is found in the finegrained layers (DiPrinzio and others, 2005; Gow and Meese, 2007a; Obbard and Baker, 2007).

In most of these cores (GRIP, GISP2 and Byrd, as well as Siple Dome), the region of smaller mean grain size and strengthened fabric lies below a region of decreased grain growth. There are a number of mechanisms which can be responsible for slowing grain growth:

1. Impurities located within the grain boundaries could hinder grain boundary migration and slow the growth process.

2. In a region with an already strong fabric, adjacent grains having similar orientation provide little driving force for one grain to grow at the expense of another (orientation pinning) (Abbruzzese and Lücke,1986; Abbruzzese and others, 1988).

3. Polygonization induced by an increase in strain after a steady-state grain size is reached can result in larger grains splitting into smaller ones having a low misorientation angle (Alley and Woods 1996; Alley and others, 1997; Thorsteinsson and others, 1997; De La Chapelle and others, 1998).

In layers above the fine-grained one at Siple Dome (i.e. in samples from 640, 670 and $700 \mathrm{~m}$ ), a bimodal grain-size distribution was observed. This could be caused by orientation pinning, where the smaller grains lacked the driving force to grow, or partial polygonization, where the larger grains were simply regions that had not yet recrystallized. The present result of low, regular misorientations across adjacent grains suggests the latter, i.e. that polygonization is taking place at depths above $700 \mathrm{~m}$.

Within the fine-grained layers themselves $(727,750$ and $770 \mathrm{~m}$ ), some type of recrystallization is probably responsible for the decrease in mean grain size. Migration recrystallization does not actually slow grain growth, but produces new, smaller grains that contribute to a reduced mean grain size. However, migration recrystallization requires temperatures greater than $-10^{\circ} \mathrm{C}$ (Alley, 1988). The englacial temperature in Siple Dome is $-14.18^{\circ} \mathrm{C}$ at $606 \mathrm{~m}$ depth, $-11.44^{\circ} \mathrm{C}$ at $706 \mathrm{~m}$, and $-8.62^{\circ} \mathrm{C}$ at $805.7 \mathrm{~m}$ (Engelhardt, 2004). Perhaps more importantly, the predominance of low angle misorientations between neighbors, irregular but not interdigitated grain boundaries, and undulose extinction in larger grains argues for polygonization. Further, we see a large proportion of low angle misorientations $\left(<10^{\circ}\right)$ between adjacent grains, particularly in the 727 and $750 \mathrm{~m}$ samples, rather than the lack of $c$-axis multi-maxima or $45^{\circ}$ off-vertical positions normally seen with migration recrystallization (Alley, 1998). The larger spread of $>10^{\circ}$ misorientations in the $770 \mathrm{~m}$ sample suggests the onset of migration recrystallization, which is consistent with the temperature at this greater depth.

Small grain size in deeper layers where migration recrystallization is not yet taking place could theoretically be related to a high impurity concentration (Alley and Woods, 1996; Thorsteinsson and others, 1997; Gow and Meese, 2007a), a 'memory' of surface temperature (at firn formation; Petit and others, 1987) or a high applied stress. The location (lattice) and relatively low number of impurities in our samples suggests they are not a factor in fabric development. The surface-temperature memory effect can produce seasonal layers of smaller crystals, but not a bimodal distribution within a layer. Further, as Alley and Woods (1996) point out, it is difficult to disambiguate the surface-temperature memory effect from seasonal impurity distribution. For our analysis, in the face of bimodal and fine-grained regions and with few impurities, in ice deep enough that seasonal variations are no longer evident, we conclude that firnification temperature is not the cause of the fabric variations we see. Therefore, applied stress is the predominant mechanism controlling grain size in this section of Siple Dome. An increase in fabric strength has been positively correlated to cumulative strain, a relationship observed and modeled by Alley (1988). Further, for subgrain rotation during high-temperature dislocation creep of dynamically recrystallized rock-forming minerals, the increase in strain corresponds to an increase in applied 
stress, and a decrease in the steady-state grain size:

$$
d=B \mathbf{b}\left(\frac{\sigma}{\mu}\right)^{-p},
$$

where $d$ is the equilibrium grain size, $B$ is a non-dimensional constant $(\sim 10), \mathbf{b}$ is the Burger's vector, $\mu$ is the shear modulus, $\sigma$ is the applied stress and $p$ is a material constant equal to 1.25 (Poirier, 1985; Shimizu, 1998). In short, grain size is inversely proportional to applied stress where polygonization is taking place.

Overall, the regions of decreased grain size between 700 and $770 \mathrm{~m}$ at Siple Dome $(700,727$ and $750 \mathrm{~m}$ ) are characterized by reduced mean grain size and strong single-maximum fabric as seen in the uncorrelated misorientations (red line) in Figure 5, with low misorientation angles between adjacent grains. These factors, as well as undulose extinction observed in large grains in optical thin sections of the preceding layers (640 and $670 \mathrm{~m}$ ), suggest that the fine-grained layers have been produced by straininduced polygonization.

The nucleation of new grains through migration recrystallization will tend to reduce overall fabric strength and contribute high angle misorientations and $45^{\circ}$ off-vertical maxima, features not observed in the 700,727 and $750 \mathrm{~m}$ samples. Even the $770 \mathrm{~m}$ sample, while possessing some higher-angle grain misorientations, is still predominantly composed of similarly oriented grains with low angle misorientations between adjacent ones.

It is difficult to determine the cause of the disturbed stratigraphy observed at depth across Siple Dome. The depth of the deepest radar-visible continuous layer $(757 \mathrm{~m})$ is very near a large and rapid change in the gas and ice isotopes (722 m) (Taylor and others, 2004b). Taylor and others (2004b) interpreted these anomalies as indicating a temperature increase of $6^{\circ} \mathrm{C}$ in just several decades. However, it is possible that crevasses extending through the firn could have provided sufficient ventilation to explain variations in the gas and ice isotopes. Crevasses on ice sheets form at either the ice-sheet surface or at its bed where the ice experiences flotation (or near-flotation) conditions (Van der Veen, 1998). Basal crevasses are observed in our radar data $(62-66 \mathrm{~km}$; Fig. 5) at the grounding line of Siple Dome. However, we do not believe that the disturbed stratigraphy results from flotation of the ice sheet, because this would require a reduction in ice-sheet thickness of $\sim 500 \mathrm{~m}$ from its present thickness. Surface crevasses become progressively buried by accumulating snow once strain is relieved. The oldest preserved surface crevasses occur near Siple Dome with ages of up to $\sim 400$ years (personal communication from B. Smith, 2010). It is not known, however, if older, more deeply buried surface crevasses could be detected in radar data. If we assume that the disturbed layers result from buried surface crevasses, it seems that the crevasses must have been large and persistent enough to infill with blowing snow of different permittivity creating a stratigraphic signature that could be preserved at the large burial depths observed in the radar. Infilling snow may have had other different properties as well (e.g. grain size or porosity) that could have affected gas diffusivity and isotopic signatures. Further, crevasses across both flanks of Siple Dome could form where the tensile stresses exceed a critical value of $\sim 100 \mathrm{kPa}$, as indicated by several studies summarized in Nath and Vaughan (2003). On the other hand, the disturbed stratigraphy revealed in the radar data could result from an unusual state of strain between 700 and $800 \mathrm{~m}$ due to some phenomena other than preserved crevasses. There may be some characteristic of the ice at this depth that makes it function as a shear layer, for example. This would be consistent with Pettit and others (2011) who suggest that the only way to match the measured strain-rate data for Siple Dome is to have a significant proportion of the strain accommodated in the region from 700 to $800 \mathrm{~m}$. Ongoing work to analyze the microstructural location of impurities in this depth range may provide more evidence.

\section{CONCLUSIONS}

Microstructural analysis of the seven samples from 640 to $790 \mathrm{~m}$ yields significant evidence that the general decrease in mean grain size and strengthening of fabric in the range $727-770 \mathrm{~m}$ is the result of strain-induced polygonization.

New, smaller grains, resulting in reduced mean grain size, are produced by recrystallization. Migration recrystallization at these depths is possible but is not what the texture suggests. The mixture of large and small (bimodal) grain size in samples from 640 and $670 \mathrm{~m}$, above the fine-grained region, and undulose extinction in larger grains within that region, suggests the initiation of polygonization. Textural and fabric evidence suggests that polygonization is the predominant recrystallization mechanism between 727 and $770 \mathrm{~m}$, where it produces a decrease in mean grain size, a single-maximum fabric and misorientations of $10-40^{\circ}$, primarily in the $c$-axis direction. That the polygonization process is strain-induced is supported by radar data that reveal stratigraphic disturbance at and below $757 \mathrm{~m}$ and by strain-rate analysis (Pettit and others, 2011) that suggests significant strain between 700 and $800 \mathrm{~m}$.

The initiation of migration recrystallization, evidenced by a multiple-maxima fabric with misorientations between maxima of $70-90^{\circ}$, is found near the transition from finegrained ice back to larger-grained ice, at $\sim 770 \mathrm{~m}$, where temperatures are higher and a greater frequency of high angle misorientations and multiple maxima is observed.

\section{ACKNOWLEDGEMENTS}

This work was funded under US National Science Foundation (NSF) grants OPP-0738975 to Baker and OPP-0538120 to Catania. The views and conclusions contained herein are those of the authors and should not be interpreted as necessarily representing official policies, either expressed or implied, of the NSF or the US Government. The authors are grateful for informative discussions with K. Taylor and J. Severinghaus, as well as for the detailed comments of two anonymous reviewers.

\section{REFERENCES}

Abbruzzese, G. and K. Lücke. 1986. A theory of texture controlled grain growth: I. Derivation and general discussion. Acta Metall. Mater., 34(5), 905-914.

Abbruzzese, G., K. Lücke and H. Eichelkraut. 1988. Computer simulation of texture-controlled grain growth. Trans. Iron Steel Inst. Jpn, 28(10), 818-825.

Alley, R.B. 1988. Fabrics in polar ice sheets: development and prediction. Science, 240(4851), 493-495.

Alley, R.B. 1992. Flow-law hypotheses for ice-sheet modeling. J. Glaciol., 38(129), 245-256. 
Alley, R.B. and G.A. Woods. 1996. Impurity influence on normal grain growth in the GISP2 ice core, Greenland. J. Glaciol., 42(141), 255-260.

Alley, R.B., J.H. Perepezko and C.R. Bentley. 1986. Grain growth in polar ice: II. Application. J. Glaciol., 32(112), 425-433.

Alley, R.B., A.J. Gow and D.A. Meese. 1995. Mapping c-axis fabrics to study physical processes in ice. J. Glaciol., 41(137), 197-203.

Alley, R.B., A.J. Gow, D.A. Meese, J.J. Fitzpatrick, E.D. Waddington and J.F. Bolzan. 1997. Grain-scale processes, folding and stratigraphic disturbance in the GISP2 ice core. J. Geophys. Res., 102(C12), 26,819-26,830.

Baker, R.W. and W.W. Gerberich. 1979. The effect of crystal size and dispersed-solid inclusions on the activation energy for creep of ice. J. Glaciol., 24(90), 179-194.

Bate, P.S., R.D. Knutsen, I. Brough and F.J. Humphreys. 2005. The characterization of low-angle boundaries by EBSD. J. Microsc., 220(1), 36-46.

Bizet, B.J.R. 2006. High resolution analysis of the NORTHGRIP ice core microstructures and fabrics: a detailed study of the Dansgaard-Oeschger events 1, 8 and 19. (MS thesis, University of Copenhagen.)

Brook, E. and 6 others. 2005. Timing of millennial-scale climate change at Siple Dome, West Antarctica, during the last glacial period. Quat. Sci. Rev., 24(12-13), 1333-1343.

Castelnau, O., G.R. Canova, R.A. Lebensohn and P. Duval. 1997. Modelling viscoplastic behavior of anisotropic polycrystalline ice with a self-consistent approach. Acta Mater., 45(11), 4823-4834.

Catania, G.A., H. Conway, C.F. Raymond and T.A. Scambos. 2005 Surface morphology and internal layer stratigraphy in the downstream end of Kamb Ice Stream, West Antarctica. J. Glaciol., 51(174), 423-431.

Catania, G.A., C.L. Hulbe and H.B. Conway. 2010. Grounding-line basal melt rates determined using radar-derived internal stratigraphy. J. Glaciol., 56(197), 545-554.

Clarke, T.S., C. Liu, N.E. Lord and C.R. Bentley. 2000. Evidence for a recently abandoned shear margin adjacent to Ice Stream B2, Antarctica, from ice-penetrating radar measurements. J. Geophys. Res., 105(B6), 13,409-13,422.

Cullen, D.C. 2002. The structure and chemistry of polar glacier ice. (PhD thesis, Dartmouth College.)

De La Chapelle, S., O. Castelnau, V. Lipenkov and P. Duval. 1998. Dynamic recrystallization and texture development in ice as revealed by the study of deep ice cores in Antarctica and Greenland. J. Geophys. Res., 103(B3), 5091-5105.

DiPrinzio, C.L., L.A. Wilen, R.B. Alley, J.J. Fitzpatrick, M.K. Spencer and A.J. Gow. 2005. Fabric and texture at Siple Dome, Antarctica. J. Glaciol., 51(173), 281-290.

Dunn, C.G. and J.L. Walter. 1966. Secondary recrystallization. In Margolin, H., ed. Recrystallization, grain growth and textures. Metals Park, OH, American Society of Metals, 461-521.

Durand, G. and 8 others. 2007. Change in ice rheology during climate variations - implications for ice flow modelling and dating of the EPICA Dome C core. Climate Past, 3(1), 155-167.

Duval, P. and C. Lorius. 1980. Crystal size and climatic record down to the last ice age from Antarctic ice. Earth Planet. Sci. Lett., 48(1), 59-64.

Engelhardt, H. 2004. Ice temperature and high geothermal flux at Siple Dome, West Antarctica, from borehole measurements. J. Glaciol., 50(169), 251-256.

Fisher, D.A. and R.M. Koerner. 1986. On the special rheological properties of ancient microparticle-laden Northern Hemisphere ice as derived from bore-hole and core measurements. J. Glaciol., 32(112), 501-510.

Glen, J.W. and J.G. Paren. 1975. The electrical properties of snow and ice. J. Glaciol., 15(73), 15-38.

Gow, A.J. and D.A. Meese. 2007a. Physical properties, crystalline textures and $c$-axis fabrics of the Siple Dome (Antarctica) ice core. J. Glaciol., 53(183), 573-584.
Gow, A.J. and D.A. Meese. 2007b. The distribution and timing of tephra deposition at Siple Dome, Antarctica: possible climatic and rheologic implications. J. Glaciol., 53(183), 585-596.

Gow, A.J. and T. Williamson. 1976. Rheological implications of the internal structure and crystal fabrics of the West Antarctic ice sheet as revealed by deep core drilling at Byrd Station. CRREL Rep. 76-35.

Gow, A.J. and 6 others. 1997. Physical and structural properties of the Greenland Ice Sheet Project 2 ice cores: a review. J. Geophys. Res., 102(C12), 26,559-26,575.

Higashi, A., S. Mae and A. Fukuda. 1968. Strength of ice single crystals in relation to the dislocation structure. Trans. Jpn Inst. Metals, 9, Suppl., 784-789.

Hooke, R.LeB., B.B. Dahlin and M.T. Kauper. 1972. Creep of ice containing dispersed fine sand. J. Glaciol., 11(63), 327-336.

Humphreys, F.J. and M. Hatherly. 2004. Recrystallization and related annealing phenomena. Second edition. Amsterdam, etc., Elsevier.

Hutchinson, J.W. 1977. Creep and plasticity of hexagonal polycrystals as related to single crystal slip. Metall. Trans., 8(9), 1465-1469.

Iliescu, D., I. Baker and X. Li. 2003. The effects of sulfuric acid on the creep, recrystallization, and electrical properties of ice. Can. J. Phys., 81(1-2), 395-400.

Iliescu, D., I. Baker and H. Chang. 2004. Determining the orientations of ice crystals using electron backscatter patterns. Microsc. Res. Tech., 63(4), 183-187.

Jacka, T.H., S. Donoghue, J. Li, W.F. Budd and R.M. Andersen. 2003. Laboratory studies of the flow rates of debris-laden ice. Ann. Glaciol., 37, 108-112.

Jacobel, R.W. and B.C. Welch. 2005. A time marker at $17.5 \mathrm{kyr}$ BP detected throughout West Antarctica. Ann. Glaciol., 41, 47-51.

Jones, S.J. and J.W. Glen. 1969. The effect of dissolved impurities on the mechanical properties of ice crystals. Philos. Mag., 19(157), 13-24.

Koerner, R.M. and D.A. Fisher. 1979. Discontinuous flow, ice texture, and dirt content in the basal layers of the Devon Island ice cap. J. Glaciol., 23(89), 209-222.

Kreutz, K.J. and P.A. Mayewski. 1999. Spatial variability of Antarctic surface snow glaciochemistry: implications for paleoatmospheric circulation reconstructions. Antarct. Sci., 11(1), 105-118.

Li, X., D. Iliescu and I. Baker. 2009. On the effects of temperature on the strength of $\mathrm{H}_{2} \mathrm{SO}_{4}$-doped ice single crystals. J. Glaciol., 55(191), 481-484.

Mackenzie, J.K. 1958. Second paper on statistics associated with the random disorientation of cubes. Biometrika, 45(1-2), 229-240.

Morawiec, A. 1995. Misorientation-angle distribution of randomly oriented symmetric objects. J. Appl. Cryst., 28(3), 289-293.

Nakamura, T. and S.J. Jones. 1970. Softening effect of dissolved hydrogen chloride in ice crystals. Scripta Metall., 4(2), 123-126.

Nakamura, T. and S.J. Jones. 1973. Mechanical properties of impure ice crystals. In Whalley, E., S.J. Jones and L.W. Gold, eds. Physics and chemistry of ice. Ottawa, Ont., Royal Society of Canada, 365-369.

Nasello, O.B., C.L. Di Prinzio and P.G. Guzmán. 2007. Grain boundary properties of ice doped with small concentrations of potassium chloride (KCl). J. Phys. Condensed Matter, 19(24), 246218. (http://iopscience.iop.org/0953-8984/19/24/246218)

Nath, P.C. and D.G. Vaughan. 2003. Subsurface crevasse formation in glaciers and ice sheets. J. Geophys. Res., 108(B1), 2020. (10.1029/2001JB000453.)

Nereson, N.A. 2000. Elevation of ice-stream margin scars after stagnation. J. Glaciol., 46(152), 111-118.

Nereson, N.A., C.F. Raymond, E.D. Waddington and R.W. Jacobel. 1998. Migration of the Siple Dome ice divide, West Antarctica. J. Glaciol., 44(148), 643-652.

Obbard, R. 2006. Microstructural determinants in glacial ice. (PhD thesis, Dartmouth College.) 
Obbard, R. and I. Baker. 2007. The microstructure of meteoric ice from Vostok, Antarctica. J. Glaciol., 53(180), 41-62.

Paterson, W.S.B. 1991. Why ice-age ice is sometimes 'soft'. Cold Reg. Sci. Technol., 20(1), 75-98.

Petit, J.R., P. Duval and C. Lorius. 1987. Long-term climatic changes indicated by crystal growth in polar ice. Nature, 326(6108), 62-64.

Pettit, E.C. 2003. Unique dynamic behaviors of ice divides: Siple Dome and the rheological properties of ice. (PhD thesis, University of Washington.)

Pettit, E.C. and E.D. Waddington. 2003. Ice flow at low deviatoric stress. J. Glaciol., 49(166), 359-369.

Pettit, E.C. and 6 others. 2011. The crossover stress, anisotropy and the ice flow law at Siple Dome, West Antarctica. J. Glaciol., 57(201), 39-52.

Plewes, L.A. and B. Hubbard. 2001. A review of the use of radioecho sounding in glaciology. Progr. Phys. Geogr., 25(2), 203-236.

Poirier, J.P. 1985. Creep of crystals. Cambridge, etc., Cambridge University Press.

Rasband, W.S. 2006. ImageJ program. Bethesda, MA, National Institutes of Health.

Retzlaff, R. and C.R. Bentley. 1993. Timing of stagnation of Ice Stream C, West Antarctica, from short-pulse radar studies of buried surface crevasses. J. Glaciol., 39(133), 553-561.

Scambos, T.A., N.A. Nereson and M.A. Fahnestock. 1998. Detailed topography of Roosevelt Island and Siple Dome, West Antarctica. Ann. Glaciol., 27, 61-67.

Shimizu, I. 1998. Stress and temperature dependence of recrystallized grain size: a subgrain misorientation model. Geophys. Res. Lett., 25(22), 4237-4240.

Siggaard-Andersen, M.-L. 2005. Analysis of soluble ions from dust and sea salt over the last glacial cycle in polar deep ice cores. (PhD thesis, University of Bremen.)

Smith, B.E., N.E. Lord and C.R. Bentley. 2002. Crevasse ages on the northern margin of Ice Stream C, West Antarctica. Ann. Glaciol., 34, 209-216.

Song, M., D.M. Cole and I. Baker. 2004. Initial experiments on the effects of particles at grain boundaries on the anelasticity and creep behavior of granular ice. Ann. Glaciol., 39, 397-401.
Song, M., D.M. Cole and I. Baker. 2005a. Creep of granular ice with and without dispersed particles. J. Glaciol., 51(173), 210-218.

Song, M., I. Baker and D.M. Cole. 2005b. The effect of particles on dynamic recrystallization and fabric development of granular ice during creep. J. Glaciol., 51(174), 377-382.

Song, M., D.M. Cole and I. Baker. 2006. An investigation of the effects of particles on creep of polycrystalline ice. Scripta Mater. 55(1), 91-94.

Song, M., D.M. Cole and I. Baker. 2007a. Effect of fine particles on the flow behavior of polycrystalline ice and glaciers: I. A dislocation-based relaxation model. Chinese J. Geophys., 50(1), 126-130.

Song, M., D.M. Cole and I. Baker. 2007b. Effect of fine particles on the flow behavior of polycrystalline ice and glaciers: II. Anelastic behavior. Chinese J. Geophys., 50(1), 1156-1160.

Song, M., I. Baker and D.M. Cole. 2008. The effect of particles on creep rate and microstructures of granular ice. J. Glaciol. 54(186), 533-537.

Sowers, T., M. Bender, D. Raynaud and Y. Korotkevich. 1992. $\delta^{15} \mathrm{~N}$ of $\mathrm{N}_{2}$ in air trapped in polar ice: a tracer of gas transport in the firn and a possible constraint on ice age-gas age differences. J. Geophys. Res., 97(D14), 15,683-15,697.

Taylor, K.C. and R.B. Alley. 2004. Two-dimensional electrical statigraphy of the Siple Dome (Antarctica) ice core. J. Glaciol., 50(169), 231-235.

Taylor, K.C. and 13 others. 2004a. Dating the Siple Dome (Antarctica) ice core by manual and computer interpretation of annual layering. J. Glaciol., 50(170), 453-461.

Taylor, K.C. and 13 others. 2004b. Abrupt climate change around 22 ka on the Siple Coast of Antarctica. Quat. Sci. Rev., 23(1-2), 7-15.

Thorsteinsson, T., J. Kipfstuhl and H. Miller. 1997. Textures and fabrics in the GRIP ice core. J. Geophys. Res., 102(C12), $26,583-26,599$.

Van der Veen, C.J. 1998. Fracture mechanics approach to penetration of bottom crevasses on glaciers. Cold Reg. Sci. Technol., 27(3), 213-223.

Wang, Y., S. Kipfstuhl, N. Azuma, T. Thorsteinsson and H. Miller. 2003. Ice-fabrics study in the upper $1500 \mathrm{~m}$ of the Dome C (East Antarctica) deep ice core. Ann. Glaciol., 37, 97-104. 